\title{
Spatial Analysis of Urban Thermal Island in Northern Iran (Case Study: Rasht City)
}

Ali Mohammadpourzeid ( $\square$ amohammadpour35@yahoo.com )

Kharazmi University https://orcid.org/0000-0003-1929-2763

\section{Bohloul Alijani}

Kharazmi University

\section{Mehry Akbary}

Kharazmi University

Parviz Zeaieanfirouzabadi

Kharazmi University

\section{Research Article}

Keywords: Urban climate, Thermal island, spatial autocorrelation, Spatial analysis, Caspian sea, Climate of Rasht

Posted Date: January 14th, 2022

DOI: https://doi.org/10.21203/rs.3.rs-1137745/v1

License: (c) (1) This work is licensed under a Creative Commons Attribution 4.0 International License. Read Full License 


\title{
Spatial analysis of urban thermal island in northern Iran
}

\author{
(Case study: Rasht City)
}

Ali Mohamadpour Zeidi ${ }^{1}$, Bohloul Alijani ${ }^{2}$, Mehry Akbary $^{3}$, Parviz Zeaieanfirouzabadi ${ }^{4}$

\begin{abstract}
Land surface temperature (LST) is one of the key parameters in hydrology, meteorology, and the surface energy balance.The one-window algorithm of Kim et al. Uses Landsat satellite imagery to model the earth's surface temperature. These trends are validated using meteorological data. Two main and basic factors play a major role in the temporal and spatial trend of the thermal islands of Rasht. These two factors of climate change that have occurred in the last two decades in the region of Gilan province and the city of Rasht. The second factor that has greatly enhanced the effect of the first factor is the human factor that has greatly included other urban factors in Rasht, including urban management and proper urban planning in the province and the city of Rasht. These two factors in the temporal and spatial trend of urban thermal islands have caused thermal islands to rapidly increase the growth of the city and urban population from the urban center to the western and southwestern regions and have very negative effects on land use changes and human areas .It has caused the construction of Rasht city.
\end{abstract}

Keywords: Urban climate, Thermal island, spatial autocorrelation, Spatial analysis, Caspian sea, Climate of Rasht

\footnotetext{
${ }^{1} \mathrm{PhD}$ student in Urban Meteorology, Kharazmi University, Tehran Address: Faculty of Geographical Sciences, Kharazmi University, TehranEmail:Amohammadpour35@yahoo.com.tell:09112925499,( Author).

${ }^{2}$ Professor of Climatology, fauclty of Geography and Director of Center of Excellence for Spatial Analysis of Environmental Hazards, Department of GeographSciences, Kharizmi University, Tehran, Address: Faculty of Geographical Sciences, Kharazmi University, Tehran Email:bralijani@gmail.com.

3 Assistant Professor Climatology PhD Climatology Kharizmi University, Tehran Address: Faculty of Geographical Sciences, Kharazmi University, Tehran Email:. mehryakbary@khu.ac.ir

${ }^{4}$ Associate Professor Geoinformatics, kharazmi University of Tehran, Address: Faculty of Geographical

Sciences, Kharazmi University, Tehran Email: rsgis1000@yahoo.com
} 


\section{1- Introduction}

It can be said that in 1950, 30\% of the world's population lived in urban areas. But by 2000 this trend had reached about $47 \%$ of the world's total population. This upward trend, along with experts' forecasts, shows that by 2030 , this trend will increase to about $60 \%$. However; The process of urbanization in many developed countries is much greater than the process of urbanization in the whole world and developing countries. At least $75 \%$ of the population of these countries now live in urban areas. This trend is expected to reach $83 \%$ of the population of these countries by 2030 [Collier, 2006]. One simple definition of urbanization is that: urbanization can be defined as the expansion of built-up areas. It can be said that in addition to the widespread social and economic effects of urbanization; It has many meteorological and climatic consequences [Conry, 2015].

According to the definition of urbanization, it has many meteorological and climatic consequences. Among them, the local consequences of urban areas in changing environmental conditions in the background (for example, global changes) are more evident than rural areas. However, rapid progress in industry and urban development has led to environmental problems such as increased energy consumption and air pollution, urban heating and even local (regional) climate change. [Oke.1982, Atkinson,2003, Arnfield,2003, Jin,.2005]. With the increasing trend of urbanization, which leads to an increase in impenetrable urban areas, thus affecting or moderating the energy balance of the city[Oke ,.1982, Sandro,.2020]. The energy-modifying effects of the city can be attributed to changes that typically lead to the transformation of open spaces such as natural soil cover and vegetation into artificial surfaces composed of concrete, asphalt and other impermeable surfaces. These processes strongly affect the changes that lead to the absorption and reflection of solar radiation and urban surface energy. Also, these changes and contradictions are strongly visible in the ambient temperature between the rural city or the urban environment and its suburbs [Aflaki , 2017; Mohajerani , 2017; Zhao,. 2016; Santamouris,2015].

This moderating phenomenon of urban energy along with global warming threatens human health and the environment [Sailor, 2004: Al-Ghussain,2019]. However, the phenomenon of urbanization and urban activities can intensify the effects of global and urban warming, as a result of 
these two trends, more populations will be exposed to heating waves (especially urban)[ Weng,2004: Dwivedi,2018: Reisi,2019: Odunuga,2015]. The result is the emergence of a phenomenon known as Urban Heat Island (UHI), which first emerged from Howard's time in the late 18th and early 19th centuries when studying London's urban climate. [Streutker,2003; Yu,2019].

Urban heat phenomenon (UHI) - a phenomenon in which the temperature in urban areas (especially downtown) is higher than in suburban areas, etc [Zhao ,2016: Zhou,2019; Oke,1982]. This clearly shows that on the one hand there has been a major human change in urban terrestrial environments, on the other hand this trend is accompanied by global warming[Clinton,2013: Zhou,2014 ]. The phenomenon of thermal islands is not specific to developed countries but to the whole world. This phenomenon acts as a cycle of climate change in the urban area and mainly changes around itself. Including has a direct effect on vegetation growth and urban climate quality[Rizwan,2007]. This trend in itself can dramatically affect human health and well-being (urban and even suburban)[ Arnfield,2003; Zhao,2016: Zhou,2014: Grimm,2008]. These side effects, which may potentially lead to increased complications such as mortality, energy consumption (especially fossil fuels) that occur in urban transportation and urban industrial areas, can even be said to have negative effects on behavior and Violent incidents affect the population of urban. The negative effects of urban warming and its associated consequences are predicted to develop rapidly throughout the world under the domination of warm urban climates[Santamouris,2015: O'Loughlin,2012: Seto,2012: Clay,2016 ]. This is especially true in developing and emerging economies, where urban populations are projected to be about 35\% higher than global urban populations[Zhou,2019].

To study the surface temperature in cities, thermal infrared (TIR) data can be used, which is widely used to recover and extract the surface temperature (LST)[ (Lo, 2003; Weng., 2004]. Ground surface temperature can be known as radiometric temperature. This temperature is taken directly from the surface temperature to be measured [Hulley, 2014: Chapman,2019]. This type of surface temperature measurement is the opposite of the measurement that is made at meteorological stations that measure surface temperature at close range [Lo, 2003]. Measurements obtained directly from satellite data allow us to perform more accurately and better in the analysis of surface temperature 
[Voogt ,1998].Data obtained from satellites in climate and urban studies are mainly useful for analyzing urban surface temperature patterns and their relationship with urban surface characteristics. Urban surface temperature can disrupt the temperature in the lower layer of the urban atmosphere, and this causes the exchange of energy in and around cities, and disrupting the climate of central cities and even the health of the urban population has negative effects[Chudnovsky., 2004: Lo., 1997; Weng, 2001, Weng, 2003; Weng., 2004 ]. The main factors that can strongly affect the temperature of the urban surface in cities can be the physical properties of different types of urban surfaces (what materials they are composed of ), the color of urban surfaces, the sky view factor, direction (geometry) of the street, Urban traffic and human activities in cities are the most important factors influencing urban surface temperature. All these processes have a direct relationship between urban planning and land use[Oke1999; Tong., 2005: Schneider,2010].

The temperature obtained from the ground has the ability to recover the city's climate variables such as evapotranspiration from the city surface and urban vegetation, heat stress that is created by the structure and geography of the city and even its effect on the amount Check soil moisture. [Agam,2008:Dousset,2003: Rodrigues de Almeida,2021:Hall,2012: Guillevic,2018: Hulley,2019: Neteler,2011: Kustas , 2009].

The purpose of this study is to analyze the spatial and temporal variables of urban thermal island in Rasht as one of the most populous northern cities in Iran .Using a time series of Landsat data in two basic periods will be performed based on the single-window model of Kim et al (2001). It will also examine the changes in the spatial and temporal pattern and timing of UHIs, as well as changes in land use patterns and land cover .This examines and understands the relationship between urban heating island and the main bio-physical stimuli in the city .

To derive city surface temperature on Landsat data, ground surface emissions must first be estimated from the NDVI index [Sobrino,2011 ]. In relation to LST and urban temperature, what matters is the response of surface temperature and its performance in areas with vegetation. Using remote sensing techniques, various vegetation indices can be evaluated and used. Establishing a link between land cover and LST can be useful for urban climate studies [Zaitunah,2018]. The NDVI 
index in the Landsat satellite image is made up of near-red and infrared bands. The value of this index is between 1 and -1. Positive values indicate healthy green cover, while negative values indicate nonvegetation cover[Weng,2004: Grover,2015].Equation (1):

$$
\varepsilon_{i}=\left\{\begin{array}{c}
a_{1 i}+\sum_{j=2}^{7} a_{j i} \rho_{j} \quad N D V I<N D V I_{S} \\
\varepsilon_{v i} P_{v}+\varepsilon_{s i}\left(1-P_{v}\right)+4 d \varepsilon P_{v}\left(1-P_{v}\right) N D V I_{S} \leq N D V I
\end{array}\right.
$$

where $\varepsilon_{i}$ is the LSE in band $6 ; \varepsilon_{s i}$ and $\varepsilon_{s i}$ are the vegetation component emissivity and background component emissivity, respectively; $\rho_{j}$ is the surface reflectance of the Operational Land Imager (OLI)band $\mathrm{j} ; a_{j i}$ is coefficient $(\mathrm{j}=1 \sim 7)$; and $P_{v}$ is the fractional vegetation cover, which can be expressed by [Carlson,1997]: Equation (2):

$$
P v=\left[\frac{N D V I-N D V I s}{N D V I v-N D V I s}\right]^{2}
$$

where NDVIv and NDVIs are the NDVI for the bare soil pixels and fully vegetated pixels, respectively. To maintain the spatial consistency, NDVIs $=0.2$ and NDVIv $=0.86$ are assigned.$d_{\varepsilon}$ represents the emissivity increment from the cavity effect caused by the multiple scattering in the pixel, and can be expressed by [Cheng et al.2017]: Equation (3):

$$
\begin{aligned}
d \varepsilon= & \left\{\frac{\varepsilon_{v j}\left(-0.435_{\varepsilon v j}+0.4343\right.}{0.985} \varepsilon_{v j} \neq 0.985\right. \\
& -0.435_{\varepsilon v j}+0.4343 \varepsilon_{v j} \neq 0.985
\end{aligned}
$$

For, the radiation temperatures measured by the radiometer were used to calculate the in-situ LSTs, and the formula is given by Equation. Th effects of emissivity and the downward sky irradiance were corrected Equation (4):

$$
\mathrm{B}\left(\mathrm{T} \_\mathrm{s}\right)=\left[\left(\mathrm{B}\left(\mathrm{T} \_\mathrm{r}\right)-(1-\varepsilon) \mathrm{L} \_(\text {sky })\right] / \varepsilon\right.
$$

where $T_{S}$ is the LST, $T_{r}$ is the radiation temperature, B is the plank function, is the emissivityof SI- 111 channel, $L_{s k y}$ is the downwelling atmospheric radiance. 
For other sites, the LST was estimated from the upwelling and downwelling longwave radiation using the following equation Equation (5):

$$
T s=\left[\frac{F^{\uparrow}-\left(1-\varepsilon_{b}\right) F^{\downarrow}}{\varepsilon_{b} \sigma}\right] 0.25
$$

where Ts is the LST, $F^{\uparrow}$ is the measured surface upwelling longwave radiation, $\varepsilon_{b}$ is the surface broadband emissivity (BBE), $\sigma$ is the Stefan-Boltzmann's constant $(5.67 \times 10-8 \mathrm{Wm}-2 \mathrm{~K}-4)$, and $F^{\downarrow}$ is the measured atmospheric downwelling longwave radiation.[Cheng, et al .2013; Yang,,2014: Wu,2014]Equation (6):

$$
\varepsilon_{b}=0.197+0.025 \varepsilon_{10}+0.057 \varepsilon_{11}+0.237 \varepsilon_{12}+0.333 \varepsilon_{13}+0.146 \varepsilon_{b}
$$

where $\varepsilon_{b}$ is the surface broadband emissivity, and $\varepsilon_{b 10}-\varepsilon_{14}$ are narrowband emissivities of five channels.

The use of spatial analysis was formed following the inefficiency of regional perspectives in problem solving. This process has been able to become widespread and efficient to this day [Menenti ,1989]. If we accept that the residuals in each model really show spatial correlation. Examining this trend by spatial autocorrelation will become a common need in geography [Kershaw , 2010]. This index measures the accumulation of values and spatial properties. This index shows the relationship of a variable (parameter) in different spatial situations. This index can take into account values that are spatially close or pairs to each other at a certain distance from each other. The more similar this process is (positive correlation), the more distant they are from each other (negative selfcorrelation). This trend is more randomly selected than waiting for pairs of observations at locations [Tobler,1970: Songchitruksa,2010]

The Moran's index was first used by Mr. Moran in the world in 1950[Moran,1950]. Which was used as the first unit of spatial autocorrelation. The values of this index vary between the values of 1 - to $1[\mathrm{Fu}, 2014]$. A value of 1 (positive) means that the complete and positive spatial 
autocorrelation between (high values or low values with) is clustered. This is while the value 1(negative) indicates a completely negative spatial autocorrelation or (checkered pattern). This is while (Global Moran's I) mostly evaluates spatial correlations or quantities. But (Local Moran's I) measure spatial association (LISA) and the degree of spatial autocorrelation in any particular location. This index well identifies the behavior of spatial cluster patterns and spatial outliers [Anselin,1995: Harries,2006: Levine, 2004: Tu,2008 ]. Equation (7):

$$
I=\frac{n \sum \Sigma w_{i j}\left(x_{i}-\bar{x}\right)\left(x_{j}-\bar{x}\right)}{w \Sigma\left(x_{i}-\bar{x}\right)^{2}}
$$

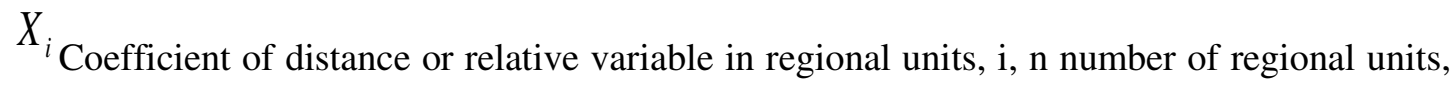

$w_{i j}$ weight (includes urban facilities).

The G statistics were developed by Getis and Ord[Ord,1995: Getis,1992], and are most commonly used to identify spatial patterns. However, this statistic, like the Moran index, can also study and identify spatial interdependence[Mitchell,2005]. Indicators like Moran are usually very general. In such a way that it can not identify local patterns in a large area. The fact is that the level of spatial dependence may have significantly different functions across space. This trend indicates that the capacity to detect and characterize the spatial heterogeneity of Gi statistics is more favorable than local Moran. It must be borne in mind that the Moran family of indices is indistinguishable from hot spots and cold spots. Therefore, Gi index is more suitable than Moran index, it can eliminate these defects [Flahaut,2003: Mitra,2009: Quddus,2008 ]. Equation (8):

$$
G(d)=\frac{\Sigma \Sigma w_{i j}(d) x_{i} x_{j}}{\Sigma \Sigma x_{i} x_{j}}
$$

Because of $i \neq j$, The general statistic $\mathrm{G}$ is defined by the distance criterion (D). Within that distance, the regional units can be considered as I neighbors. Weight wij (d) is equal to 1.

\section{Study Area and Climate Data}




\section{2-1. Study area}

The city of Rasht has been selected for this article due to its historical, economic and social importance in northern Iran. The city of Rasht is located in the center of the Gilan Plain, between 49 degrees and 35 minutes and 45 seconds east longitude and 37 degrees and 16 minutes and 30 seconds north latitude. Its area is about 10240 hectares. Rasht is considered as the first and largest urban point of the province and the southern shore of the Caspian Sea and as one of the largest cities in the country with a population of 500,000 to 1 million people and the political and administrative center of Gilan province. Figure (1) shows the geographical location of the study area.

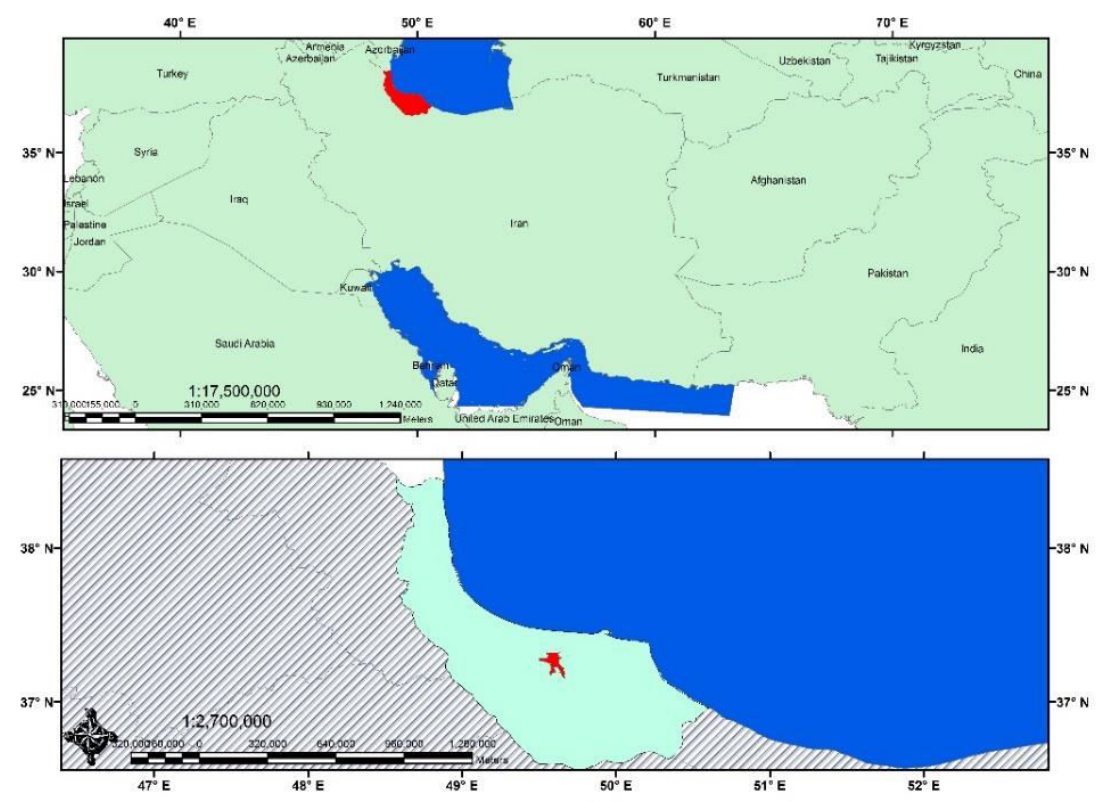

Figure 1. Geographical location of Rasht

Rasht has a temperate and humid climate in Iran. It has cold and rainy winters under the influence of Sub Polar Low,westerly winds, Siberian High Pressuer, High Pressuer Black Sea, which plays a role in heavy rainfall in these areas ;This role, especially by passing Siberian High Pressuer through the warm sea of the Caspian Sea, receives sufficient moisture and creates a lot of rainfall around $(1000 \mathrm{~mm})$. This is despite the fact that it is different in summer than in winter. In this season, the Mediterranean climate is under the domination of the Sub Tropical High Pressure . Throughout this period, hot and muggy conditions prevail in the city. Due to the social, economic, demographic 
and climatic conditions prevailing in the city of Rasht, it is rapidly expanding; This expansion has led to complex, unbalanced and compact urban structures and land use relocation to new urban areas.

\section{2-2. methodology}

In this research, two types of data have been used to extract the thermal island in Rasht. The images extracted from Landsat $7($ ETM+) are extracted from the USGS site, respectively. The second parameter used is the daily climatic data of the meteorological station in the city Rasht which has been extracted from the Meteorological Organization of Iran. For extraction and calculation of urban surface temperature for this purpose was studied based on two periods. The first period (2000-2005) and the second period (2010-2017). These periods were extracted as an image in these two periods as an average of 3 warm months of the year (summer season). Because the study area has many cloudy days, the extracted images have less than $20 \%$ cloud. Then, for geometric corrections, topographic maps of the city Rasht were used. As a result, all RMS error corrections less than 0.5 were used. Also, hourly meteorological data of synoptic stations located in the city Rasht were used to calculate the parameters related to temperature extraction. Since the satellite time is 9:45 local time and the difference between Tehran and Greenwich Mean Time is 3 hours and 30 minutes, the data was used to compare the 6 o'clock Greenwich Mean Time data at Rasht station. Then, to extract the ground surface temperature, the thermal band data of the Landsat 7 sensor were used from the single-band algorithm proposed by Kim et al. Finally, after extracting the surface temperature from the images, the thermal island is examined in terms of time and space. Then the thermal island based on techniques and spatial analysis including autocorrelation, local and regional Moran, Gi statistics and clustering of hot and cold areas of surface temperature in Rasht has been studied.

\section{Results and discussion}

In order to extract the surface temperature of Rasht in the first stage, the vegetation of the city was evaluated based on the index (NDVI) for the studied years. The results of this index are given in Table (1). This index can be considered as one of the most important 
stages of urban temperature extraction; Based on which it provides an overview of land use conditions in cities.

Table 1. The trend of NDVI index in the studied years.

\begin{tabular}{rrrrrrrrrrr}
\hline year & 2000 & 2005 & 2010 & 2011 & 2012 & 2013 & 2014 & 2015 & 2016 & 2017 \\
\hline $\begin{array}{c}\text { NDVI } \\
\text { index }\end{array}$ & 43.01 & 38.27 & 42.13 & 38.14 & 42.42 & 34.78 & 26.89 & 41.48 & 42.77 & 32.22 \\
& & & & & & & &
\end{tabular}

According to the results of the vegetation index of Rasht, on average, this trend covers about $38.21 \%$ of the city in the whole study period. This is while based on the geographical and natural location of Rasht city and urban planning conditions, this index fluctuates sinusoidal during the period. Depending on all of these conditions, in the first 2000 year, which is the base year; The trend of this index has reached its maximum which is about $43.01 \%$ of the total city. This trend this year is higher than the whole period and its average. This is while in the 2014-year urban planning conditions and land use changes in Rasht were very fast; On the other hand, climatic conditions in this year have reduced this index in the entire study period, which has reached about $26.89 \%$ of the total city.

This year is known as one of the most harmful vegetation conditions in Rasht. What is important about the vegetation index of Rasht is that in the 2000 year the focus of urban construction or in other words changes in urban land use in a focal point and the city center has been focused. However, all around the city in the form of agricultural fields, gardens, orchards and water reservoirs collected from rainwater and local rivers, has created a rural-urban area in the shortest distance from the city center of Rasht. This is while in the 2010 year the urban development of Rasht has been increasingly stretched in different directions, including north, west and southwest. This urban creep caused the melody of rural-urban land use changes around the city of Rasht. This is while due to the geographical, historical and political, economic and social conditions of Rasht in northern Iran; In the 2017 year this urban creep will spread in all directions. It can be said that the city of Rasht is growing as a metropolis in northern Iran by swallowing the suburbs, towns and small towns around. 
Once the vegetation results of Rasht city are known, in the next step, we will extract the surface temperature. For this purpose, this extraction is based on the one-window algorithm of Kim et al. (2001). The results obtained from this method along with the actual temperature of Rasht meteorological station are given in Table (2).

Table 2. Temperature was calculated from three indicators: List, Ta and Ta.

\begin{tabular}{|c|c|c|c|c|c|c|c|c|c|c|}
\hline $\begin{array}{l}\text { Rasht } \\
\text { station }\end{array}$ & 2000 & 2005 & 2010 & 2011 & 2012 & 2013 & 2014 & 2015 & 2016 & 2017 \\
\hline $\begin{array}{l}\text { Calculated } \\
\text { surface } \\
\text { temperature } \\
\text { LST }\end{array}$ & 31.83 & 35.64 & 39.89 & 38.25 & 25.36 & 26.85 & 39.55 & 35.29 & 32.9 & 39.09 \\
\hline $\begin{array}{l}\text { Calculated } \\
\text { surface } \\
\text { temperature } \\
\text { Ts }\end{array}$ & 31.7 & 29.54 & 31.71 & 29.18 & 21.01 & 25.3 & 30.37 & 28.34 & 24.1 & 26.74 \\
\hline $\begin{array}{l}\text { Calculated } \\
\text { surface } \\
\text { temperature } \\
\text { Ta }\end{array}$ & 31.13 & 29 & 30 & 30 & 25.1 & 27.4 & 29.5 & 27.8 & 30.5 & 26.46 \\
\hline
\end{tabular}

According to the results, the average LST temperature in Rasht in the whole study period is 34.46 degrees Celsius. This is while in the years 2012, 2013 and also 2016, due to the fact that the amount of clouds in the two months of these years was more than $20 \%$, an image of a month in these years had to be used. Temperature results showed that in the 6 years studied, the average LST temperature is higher than the average temperature. This is while the highest values related to 2010 and 2014 have reached their temperatures of 39.89 and 39.55, respectively. This is while the temperature extracted from the pictures of Rasht station in these two years are 31.71 and 30.37 degrees, respectively; And the temperature of the meteorological station on that day reached 30 and 29.5 degrees Celsius. Sinusoidal conditions of Rasht surface temperature on the one hand to the prevailing climate in the warm period of the year which is under the pressure of the subtropical. On the other hand, by combining the humidity of the Caspian Sea, it has created a very sultry and hot 
situation in the city of Rasht. However, the urban structure, materials and land use change of urban lands are very effective in maintaining and expanding the temperature of the city. These factors are involved in creating heat stress as a result of creating thermal islands in all levels and urban dimensions. However, based on the results of the correlation between Ta and Ts indices, it indicates that there is a correlation between these two indices at the error level of 0.05 and at the $95 \%$ confidence level. The significant relationship between the two indicators has reached about 0.689 positive. This indicates that about $69 \%$ of the two temperatures Ta and Ts in the city of Rasht is directly related.

After obtaining the surface temperature of Rasht, in order to understand this trend correctly, using two parameters of mean and standard deviation of the data, the temperature of the city was divided into thermal classes. Based on the classification, the temperature of Rasht city was divided into 3 categories, which include; Warm, medium and cold areas. The results of this classification are given in Figure (2).

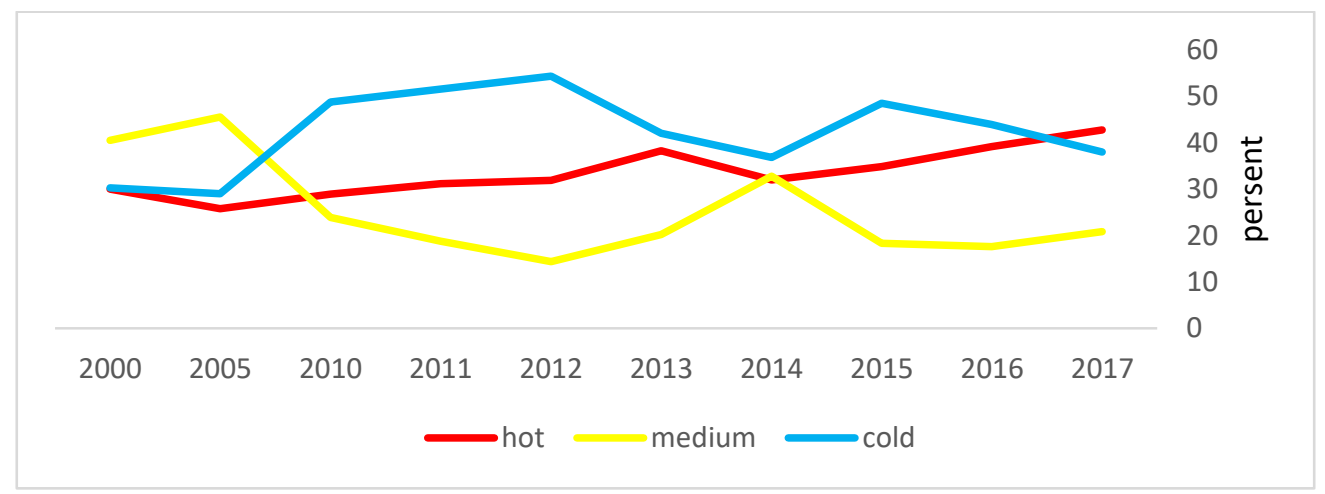

Figure 2. Area of hot, medium and cold spots in Rasht

Based on the results obtained from this classification, in the whole studied period, on average, warm, medium and cold regions in Rasht were about $33.4 \%, 25.25 \%, 42.30 \%$, respectively. However, in 2017 alone, warm urban areas reached about $42.77 \%$ of the total city, due to widespread changes in urban land use and climate change in the city. The lowest warm area in the city is about $25.74 \%$ in 2005 . This is while this year the most area of cold urban areas has reached about $30 \%$. The 
average of cold areas in this city is about $42 \%$ of the city area in the study period. This is while there is a significant relationship between vegetation index and cold regions that this index reaches 0.02 .

The temperature zones of the city indicate the thermal conditions of the city, while the intensity of the thermal islands of the city shows the effects of these zones in the city. According to the results obtained from the intensity of thermal islands of the city (URI) in the study period, the average of this index in Rasht is about $0.29 \%$. The results of this index are given in Figure (3).

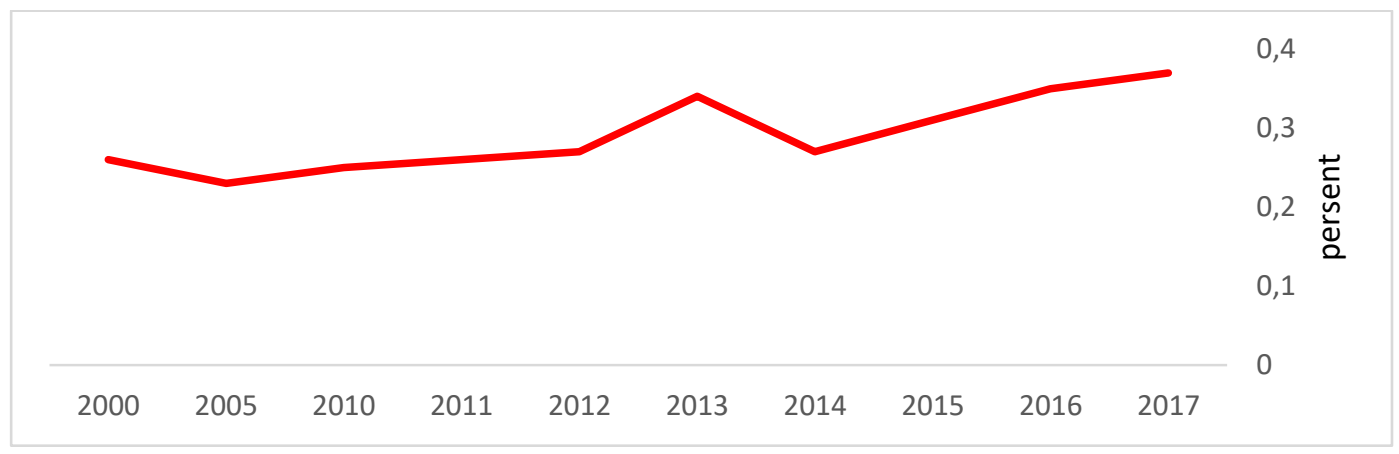

Figure 3. Intensity of thermal islands in Rasht

The highest trend of this index dates back to 2017, which has reached about $37 \%$ of the city. The lowest trend dates back to 2005 , when it reaches about $25 \%$ of the city. The correlation statistics between heat intensity and hot areas in the city were at the level of $99 \%$, indicating a strong relationship between these two indicators.

What should be considered in the process of thermal islands and temperature of urban areas of Rasht can be divided into two main factors that include many details. Before entering into the important factors, an important point in this regard should be mentioned. The city of Rasht has a unique geographical location in the north of Iran. As mentioned in its geographical and climatic conditions, another factor is the location of the city in the south of the Caspian Sea, this neighborhood as a source of moisture and energy and the entry of different climates in all seasons. Existence of soil and other suitable environmental conditions and other infrastructures should also be considered. These special climatic and geographical conditions of Rasht city make it suitable for living in the city for urban residents. But important factors in this area have disrupted it. The first factor is the spread of 
climate change in the world, the region and (local) that has caused the urban climate of Rasht to deviate from normal. These climate changes have caused the average temperature of the study period to experience about 4.5 degrees Celsius compared to the long-term growth period. The long-term average temperature leading up to 2017 was about $25.01^{\circ} \mathrm{C}$. But what the average temperature from 2000 to 2017 shows is an increase of 29.47 degrees Celsius. Another second factor that has contributed to these temperature conditions in the city is the lack of proper urban planning and misunderstanding of this issue (urban climate change). This has led to an uncontrolled increase in urban space and extensive changes in urban land use that have created thermal islands in the city of Rasht. Figure (4) shows the trend of thermal islands in Rasht in three time periods in 2000, 2010 and 2017.
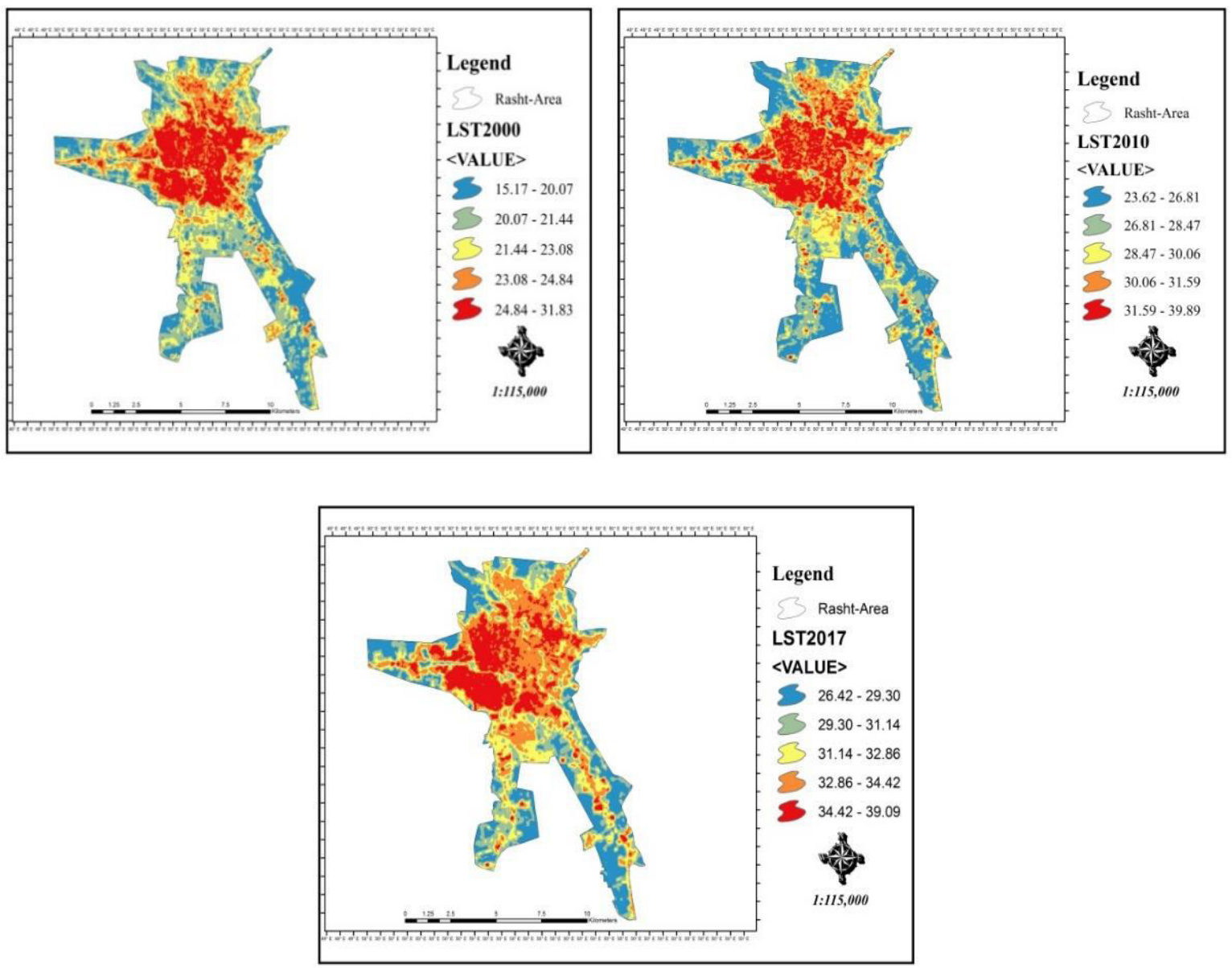

Figure 4. Distribution of thermal islands in Rasht

In the following, the spatial conditions of the thermal islands of Rasht are discussed. What is certain is that spatial and geographical analysis are often multivariate and multi-criteria. Geographers, 


\begin{tabular}{|c|c|c|c|c|c|c|c|c|c|c|}
\hline & 2000 & 2005 & 2010 & 2011 & 2012 & 2013 & 2014 & 2015 & 2016 & 2017 \\
\hline $\begin{array}{l}\text { Moran' } \\
\text { s Index }\end{array}$ & 0.996301 & 0.996301 & 0.996301 & 0.996301 & 0.979373 & 0.977745 & 0.962966 & 0.993263 & 0.992641 & 0.989329 \\
\hline $\begin{array}{c}\text { Expect } \\
\text { ed } \\
\text { Index }\end{array}$ & $\begin{array}{c}- \\
0.000009\end{array}$ & $\begin{array}{c}- \\
0.000009\end{array}$ & $\stackrel{-}{-}$ & $\stackrel{-}{-}$ & $\begin{array}{c}- \\
0.000009\end{array}$ & $\begin{array}{c}- \\
0.000009\end{array}$ & $\begin{array}{c}- \\
0.000009\end{array}$ & $\begin{array}{c}- \\
0.000009\end{array}$ & $\begin{array}{c}- \\
0.000009\end{array}$ & $\begin{array}{c}- \\
0.000009\end{array}$ \\
\hline $\begin{array}{c}\text { Varian } \\
\text { ce }\end{array}$ & 0.000004 & 0.000004 & 0.000004 & 0.000004 & 0.000004 & 0.000004 & 0.000004 & 0.000004 & 0.000004 & 0.000004 \\
\hline Z-score & $\begin{array}{c}471.6163 \\
58\end{array}$ & $\begin{array}{c}471.6163 \\
58\end{array}$ & $\begin{array}{c}471.6163 \\
58\end{array}$ & $\begin{array}{c}471.6163 \\
58\end{array}$ & $\begin{array}{c}463.6029 \\
78\end{array}$ & $\begin{array}{c}462.8325 \\
22\end{array}$ & $\begin{array}{c}455.8379 \\
88\end{array}$ & $\begin{array}{c}470.1785 \\
41\end{array}$ & $\begin{array}{c}469.8836 \\
86\end{array}$ & $\begin{array}{c}468.3161 \\
65\end{array}$ \\
\hline p-value & 0.000000 & 0.000000 & 0.000000 & 0.000000 & 0.000000 & 0.000000 & 0.000000 & 0.000000 & 0.000000 & 0.000000 \\
\hline
\end{tabular}

planners, and spatial decision makers are faced with a wide range of data and information to solve their problems, which are often very complex and difficult to use, integrate, and analyze due to their large size and different natures. One of the indicators that can be used in this process is the Moran index. This index will show whether the trend of thermal islands in Rasht has spatial auto correlation or not. The results of this Moran index are given in Table (3).

Table 3. Moran results in the studied years in Rasht

The results of Moran index in Rasht show that its value is above $0.99 \%$ in other years other than 2012, 2013, 2014, 2017. This is while for the years mentioned, it is $0.97,0.96$ and 0.98 percent, respectively. The trend of Moran index in Rasht urban heat islands in the study period shows that the trend of urban heat islands has a high cluster pattern and fluctuates at the level of 96 to $99 \%$. Furthermore, in 2014, the trend of this index reached its lowest level of 96 percent. Moran z statistic index in the study period in Rasht is between 455.84 to 471.62 ; Furthermore the p-value index throughout the period is 0.000 , which indicates a highly focused clustering pattern. Considering the values of these two Moran and p-value indices, the hypothesis of lack of spatial auto correlation between the thermal islands of the city in the studied years can be rejected. If we divide the thermal islands in space normally in the years studied in Rasht, the global Moran index is about -0.000009 . This index and the amount of Moran in 2012, 2013, 2014, which has reached its lowest point, 
indicates the fact that there are differences in different years at different scales. This is a situation that

\begin{tabular}{|c|c|c|c|c|c|c|c|c|c|c|}
\hline & 2000 & 2005 & 2010 & 2011 & 2012 & 2013 & 2014 & 2015 & 2016 & 2017 \\
\hline $\begin{array}{l}\text { Observ } \\
\text { ed } \\
\text { General } \\
\text { G }\end{array}$ & 0.000002 & 0.000002 & 0.000002 & 0.000002 & 0.000001 & 0.000001 & 0.000001 & 0.000001 & 0.000001 & 0.000001 \\
\hline $\begin{array}{l}\text { Expect } \\
\text { ed } \\
\text { General } \\
\text { G }\end{array}$ & 0.000001 & 0.000001 & 0.000001 & 0.000001 & 0.000001 & 0.000001 & 0.000001 & 0.000001 & 0.000001 & 0.000001 \\
\hline $\begin{array}{l}\text { Varianc } \\
\mathrm{e}\end{array}$ & 0.000000 & 0.000000 & 0.000000 & 0.000000 & 0.000000 & 0.000000 & 0.000000 & 0.000000 & 0.000000 & 0.000000 \\
\hline z-score & $\begin{array}{l}452.8533 \\
58\end{array}$ & $\begin{array}{l}452.8533 \\
58\end{array}$ & $\begin{array}{l}452.8533 \\
58\end{array}$ & $\begin{array}{l}452.8533 \\
58\end{array}$ & $\begin{array}{l}299.7751 \\
06\end{array}$ & $\begin{array}{l}294.8367 \\
30\end{array}$ & $\begin{array}{l}208.6546 \\
50\end{array}$ & $\begin{array}{l}222.0024 \\
63\end{array}$ & $\begin{array}{l}268.9051 \\
36\end{array}$ & $\begin{array}{l}278.2596 \\
63\end{array}$ \\
\hline p-value & 0.000000 & 0.000000 & 0.000000 & 0.000000 & 0.000000 & 0.000000 & 0.000000 & 0.000000 & 0.000000 & 0.000000 \\
\hline
\end{tabular}

in other years this index is closer to one, the result of which is its spatial clustering with higher changes in the size of the neighborhood unit. Therefore, due to the increase in thermal islands, changes in the size of this index in the whole city will affect neighborhood units. This is true for the warm period we have studied in this study.

Considering that global Moran self-solidarity only shows whether our pattern is clustered or not? For this reason, local Moran is used to show the spatial distribution of the pattern governing the thermal islands in the study period. The results of local Moran analysis of thermal islands in Rasht show how this pattern is distributed in space (scattered-cluster-random). The value of this statistic can be interpreted and analyzed within the standard p-value score. Table (4) shows the results of local Moran in Rasht.

Table 4. local Moran results in the studied years in Rasht

The results of this index in Rasht show that the p-value is at a confidence level of 0.000 or 99\%. This trend indicates the impact of the city's thermal islands from local conditions such as land use, vegetation, water resources in Rasht. This is in the situation that the local statistics in Rasht is between 0.000001 to 0.000002 , the variance in the place was 0.00000 or $99 \%$, the normalized index in Rasht is about 0.000001 . The conditions of local Moran clusters of H-H clusters in Rasht during 2000 show the highest concentration in the center of the city and sparsely and slightly in the west and east 
of the city. This is while in most other parts of the city there are no significant dispersions. This is while the most clustered concentration L-L is in the southwestern center of the city towards the industrial areas of Rasht. This is while in an area of the southeast and spots are also seen in the west. In 2010, the areas without trends decreased rapidly, and quickly replaced the L-L areas in these areas, and this trend has even extended to the east and north of the city. This is while the H-H clusters have expanded to the center of the city and to the west of the city this year. But the trend of this index in 2017 in Rasht has changed in a different way. This trend has grown in the southeastern parts and east, north and west coasts of the city with L-L clusters, especially in the southeastern regions, while in the southwestern regions, this index has decreased and the area of without trends. Areas has increased. The $\mathrm{H}-\mathrm{H}$ cluster index has reached its lowest area this year and has expanded more in the center of the city to the west of the city and the central areas that were affected by the conditions of the H-H cluster in previous years have become areas without trends. The results are shown in Figure (5).
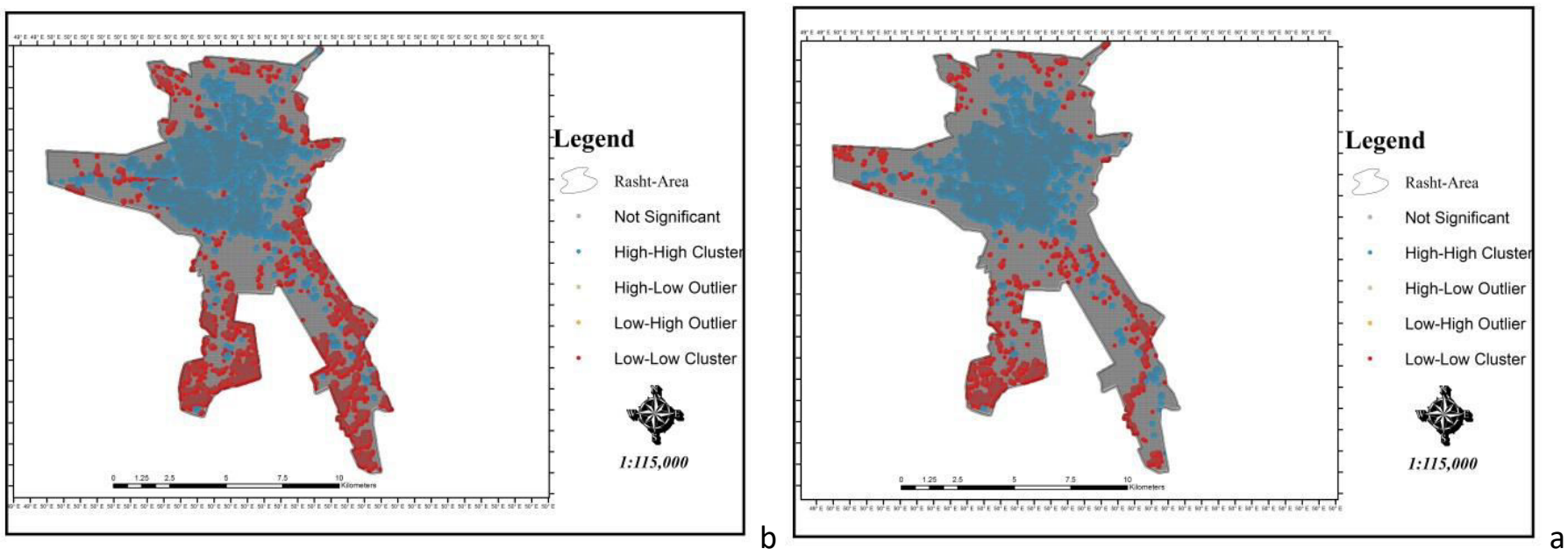


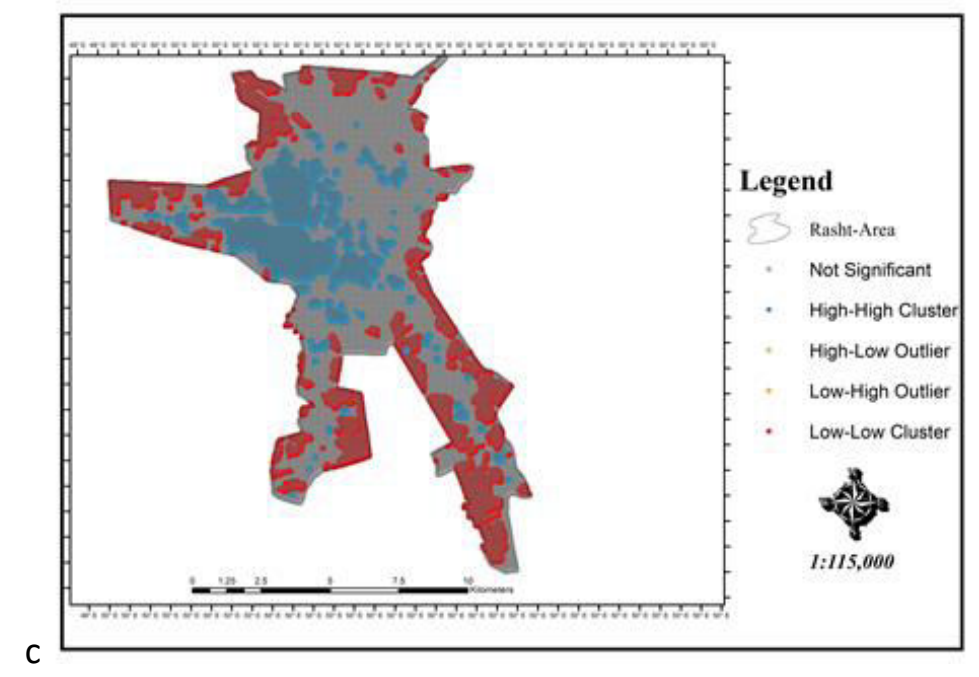

Figure 5. Results of local Moran in Rasht-a:2000, b:2010,c:2017

So far, those urban areas where thermal islands with positive spatial correlation (high heat cluster) and negative (low heat cluster) have been identified, but in order to ensure areas with high and low value clusters of the index HotSpot is used. This index is calculated for each complication in the data, It is a kind of scoring to the $\mathrm{z}$ index. The larger the $\mathrm{z}$ value, the more clustered and hot the high values are. Conversely if this happens; Intense clustering takes low values and actually shows cold spots. The results are given in Figure (6).
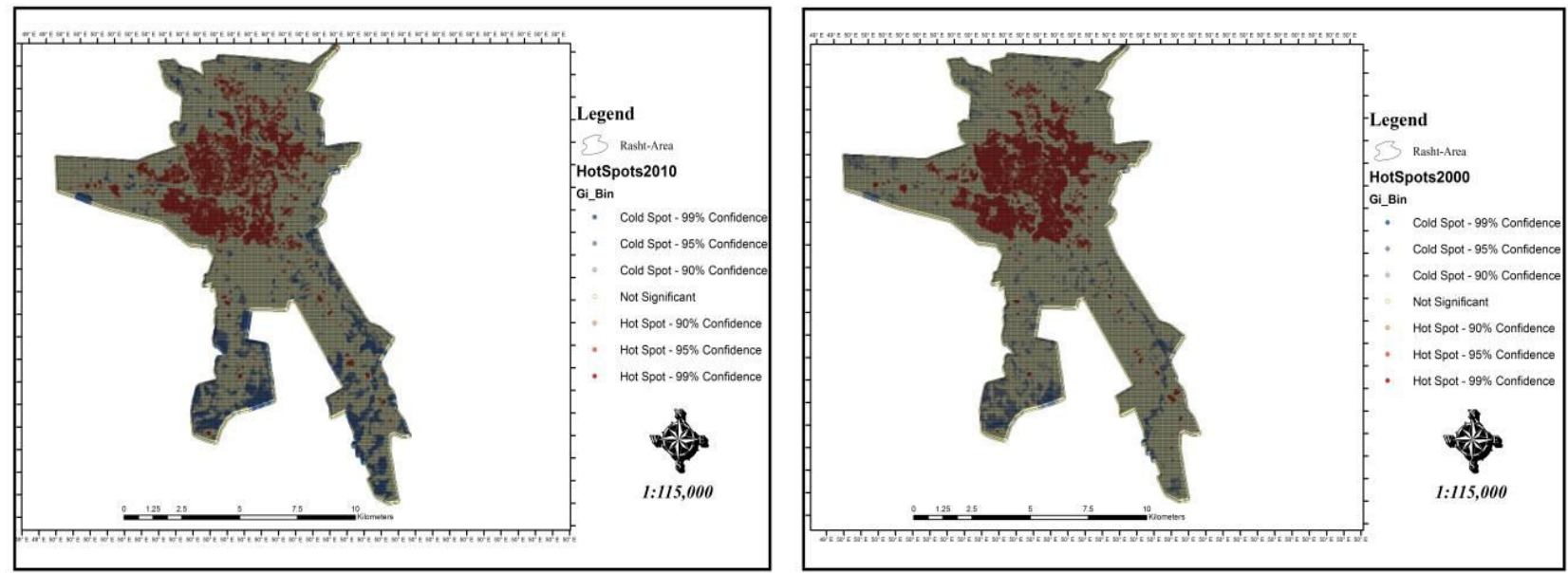


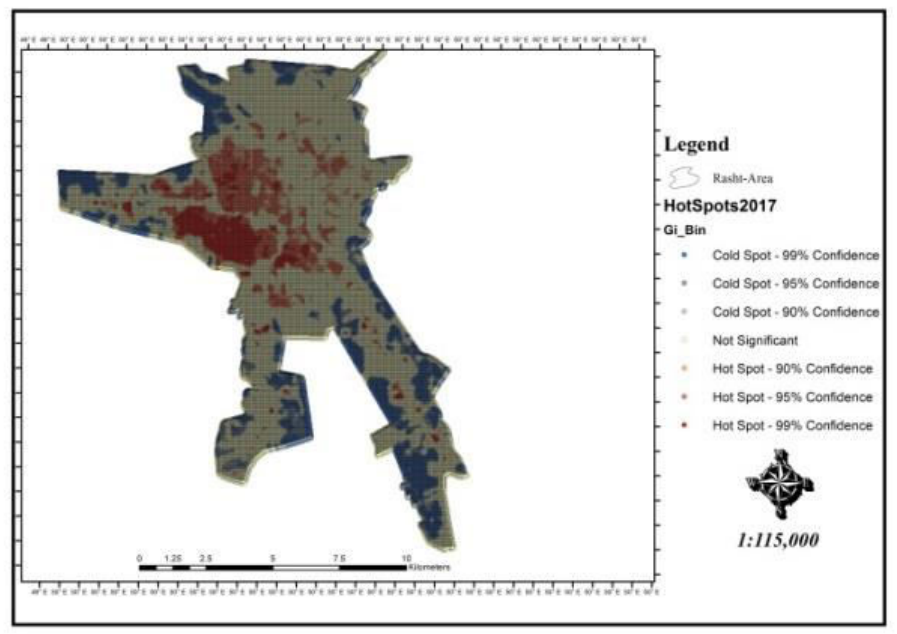

Figure 6. Hot Spot results in Rasht

Analysis of hot and cold urban spots in 2000 shows that most of the city area has a trend index. This is while the hot spots that (in the level of $99 \%$ confidence) are right in the center of Rasht, but as it moves north of the city, this trend is reduced to $95 \%$ confidence. This indicates that the trend of urban land use change to the north of the city has been reduced and this trend is becoming more uniform. Hotspots are also scattered in the west, southwest and east of the city. This year's cold spots can be perfectly matched with the Zarjoob River, which runs from the southeastern tip to the city center, and this trend indicates a 90 to $95 \%$ confidence level. The cold spots in the south-eastern and western parts are exactly in line with the water resources that exist in the urban area. This is while the cold spots are visible in a limited and narrow way in the west and east of the city at the level of 95\%. In 2010, the trend of index area (without trends) in the city is reduced, especially in the southwest and east. The cold spots this year are again consistent with the rivers and water sources that exist in different parts of the city. In the same year, the cold spots that existed narrowly along the urban boundaries in the base year have greatly increased and spread. Hot spots are scattered throughout the city except the city center, these spots are also spread to the west and southwest; This year, hot spots are at a confidence level of 90 to $95 \%$; Which goes southwest at $99 \%$ confidence level. Scattered spots are also formed in the east, south and north at a confidence level of 90 to $95 \%$. The trend of this index this year shows that factors such as growth without urban planning (lack of urban planning), land use change and climate change have been involved in the expansion of thermal islands and hot 
and cold spots in Rasht. This year, the cold spots in the city have spread rapidly in the northern, northwestern and western border areas of the city, but in the southwestern parts, this trend has sharply decreased and has given way to a without trends index. This is while the without trends index has also increased in the southeastern part to the south of the city. What is important in Rasht is that the hot spots at the beginning of the study period correspond exactly to the city center, and this trend has changed over the years until 2017, when it was moved from the city center to the west and southwest. These stains have been reduced from $99 \%$ confidence level. This year, most of the area of the city center is covered by a without trends index. This trend shows that the city of Rasht has become a city with several urban centers compared to previous years without proper and scientific urban planning and extensive land use changes and without considering climate change.

\section{Conclusions}

It is a well-known fact that the development of cities causes climate change, including the creation of urban heat islands in urban areas. With increasing urbanization, the urban heat island will have a greater impact on urban residents. In this study, the spatial and temporal analysis of the thermal island in the city of Rasht in the south of the Caspian Sea has been studied. The method used in this research is Kim's one-window model and has been done for time periods (2000 to 2005) and (2010 to 2017). The results show that on average during the study period about $39 \%$ of the city of Rasht has vegetation. Considering these conditions, the results obtained from the values of $\mathrm{Ts}$ and $\mathrm{Ta}$ temperatures in the study period were about $0.41^{\circ} \mathrm{C}$. Which is highly dependent on the geographical conditions of the city, climate change and changes in urban land use. This is while the highest average of hot zone in the study period in 2017 reached $43 \%$ of the urban area. These conditions show well that the urban temperature trend in Rasht has increased, which based on the long-term average until 2017, the average temperature was about 25.01 degrees Celsius. This is while the average temperature of the study period has reached about $29.47^{\circ} \mathrm{C}$. Which indicates a growth of $4.5^{\circ} \mathrm{C}$, which is very effective in hot urban areas. These climatic conditions with the lack of urban planning are effective in intensifying the thermal islands. The findings of Kim et al. (2005) are in this direction. 
This is while the results of spatio-temporal analysis of Rasht urban heat islands show a confidence level of $99 \%$ to $96 \%$. This trend indicates that the urban heat islands of Rasht have a cluster pattern during the years under study. This is while the local Moran index has a p-value of 0.000 during the years under study, which well shows that urban heat islands are related to local conditions such as urban structure, land use, vegetation and altitude. This is while the G statistic index is at the level of $99 \%$ confidence. This trend is consistent with the developed and active urban areas of Rasht. The findings are consistent with the results of research by Batista Silva (2017).

The results of the trends in the thermal islands of Rasht show that in 2010 the focus is on the city center. Which indicates that the islands are concentrated with the old areas of the city. This is while in 2010, the trend has crawled to most of the city and has grown in isolated and linear parts in the southeastern parts of the city. This trend in 2017 has shifted the focus away from the city center to the west and southwest of the city. This focus is on the central parts and less. This trend shows that the city of Rasht is changing into a multi-nuclear city and very chaotic. There is a more intense linear and point trend in the southeast. This trend has appeared in the southwest as single spots.

According to the obtained results, it is necessary to point out two main points in the urban thermal islands of Rasht, the first of which is; Climate change in the study areas and the second case, which is more important than the first factor and has a greater impact on it; It is a human factor that includes the lack of proper economic and social planning and the lack of proper urban planning, which has doubled the effects of the thermal islands in this city

Author Contributions: Article on the doctoral dissertation of the Department of Urban Climatology, Kharazmi University of Tehran, to the supervising professor, Professor Behlool Alijani, Dr. Mehri Akbari, and also Dr. Parviz Ziaian Firouzabadi, who have assisted in compiling and writing this thesis.

\section{Code availability}

Yes. 


\section{Funding}

The authors received no financial support for the research, authorship, and/or publication of this article.

\section{Author information}

\section{Affiliations}

Department of Climatology, Faculty of Geographical Sciences, Kharazmi University, Tehran, Iran

Ali Mohamadpour Zeidi , Bohloul Alijani , Mehry Akbary , Parviz Zeaiean Firouzabadi

\section{Contributions}

All authors contributed to the study conception and design. Material preparation, data collection and analysis were performed by [Ali Mohamadpour Zeidi], [Bohloul Alijani , Mehry Akbary , Parviz Zeaiean Firouzabadi]. The first draft of the manuscript was written by [Ali Mohamadpour Zeidi]. and all authors commented on previous versions of the manuscript. All authors read and approved the final manuscript.

\section{Corresponding author}

Correspondence to Ali Mohamadpour Zeidi

\section{Ethics declarations}

\section{Ethics approval}

Not applicable, because this article does not contain any studies with human or animal subjects.

\section{Consent to participate}

The data of this research were not prepared through a questionnaire.

\section{Consent for publication}


There is no conflict of interest regarding the publication of this article. The authors of the article make sure that everyone agrees to submit the article and is aware of the submission

\section{Conflict of interest}

The authors declare no conflict of interest.

\section{References}

1- Anselin, L.(1995), Local indicators of spatial association - LISA. Geogr. Anal., 27, 93-115. doi.org/10.1111/j.1538-4632.1995.tb00338.x.

2- Atkinson, B. W,(2003),Numerical modeling of urban heat island intensity. Bound.-Layer Meteor., , 109, 285-310. doi.org/10.1023/A:1025820326672.

3- Arnfield, A. J., Two decades of urban climate research,(2003), A review of turbulence, exchanges of energy and water, and the urban heat island. Int. J. Climatol, 23, 1-26. doi.org/10.1002/joc.859.

4- Aflaki, A, Mirnezhad, M, Ghaffarianhoseini ,A, Ghaffarianhoseini ,A ,(2017) Urban heat island mitigation strategies: a stateof- the-art review on Kuala Lumpur Singapore and Hong Kong. Cities 62(2017):131-145, doi.org/10.1016/j.cities.2016.09.003.

5- Al-Ghussain, L.(2019), Global warming: Review on driving forces and mitigation. Environ. Prog. Sustain. Energy, 38, 13-21. doi.org/10.1002/ep.13041.

6- Agam, N.; Kustas, W.P.; Anderson, M.C.; Li, F.; Colaizzi, P.D.(2008), Utility of thermal image sharpening for monitoring field scale evapotranspiration over rainfed and irrigated agricultural regions. Geophys. Res. Lett, 35, L02402, 1-7, doi:10.1029/2007GL032195.

7- Batista Silva, F, Maria Longo,K, Maria Longo,F,(2017), Spatial and Temporal Variability Patterns of the Urban Heat Island in São Paulo, journal Environments, 4, 27; doi:10.3390/environments4020027.

8- Carlson, T.N.; Ripley,(1997), D.A. On the relation between ndvi, fractional vegetation cover, and leaf area index. Remote Sens. Environ., 62, 241-252. doi.org/10.1016/S00344257(97)00104-1.

9- Cheng, J.; Liang, S.; Nie, A.; Liu, Q.(2017), Is there a physical linkage between surface emissive and reflective variables over non-vegetated surfaces? J. Indian Soc. Remote Sens., 46, 591-596. doi.org/10.1007/s12524-017-0713-7.

10- Cheng, J.; Liang, S.; Yao, Y.; Zhang, X.(2013), Estimating the optimal broadband emissivity spectral range for calculating surface longwave net radiation. IEEE Geosci. Remote Sens. Lett, 10, 401-405. DOI: 10.1109/LGRS.2012.2206367.

11- Collier, G.(2006), The impact of urban areas on weather, METEOROLOGICAL,132, pp. 125 .doi.org/10.1256/qj.05.199.

12- CONRY ,PATRICK, ASHISH SHARMA, MARK J. POTOSNAK, LAURA S. LEO, EDWARD BENSMAN, JESSICA J. HELLMANN, AND HARINDRA J. S. FERNANDO,2015, Chicago's Heat Island and Climate Change: Bridging the Scales via Dynamical Downscaling, JOURNAL OF APPLIED METEOROLOGY AND CLIMATOLOGY VOLUME 54, DOI: 10.1175/JAMC-D-14-0241.1.

13- Chudnovsky, A., E. Ben-Dor, and H. Saaroni, (2004),Diurnal thermal behavior of selected urban objects using remote sensing measurements, Energy and Buildings, 36:1063-1074. doi.org/10.1016/j.enbuild.2004.01.052.

14- Chapman, S.; Thatcher, M.; Salazar, A.; Watson, J.E.M.; McAlpine, C.A.(2019), The impact of climate change and urban growth on urban climate and heat stress in a subtropical city. Int. J. Climatol, 39, 3013-3030. doi.org/10.1002/joc.5998. 
15- Clay, R.; Guan, H.;Wild, N.; Bennett, J.; Vinodkumar; Ewenz, C.(2016), Urban heat island traverses in the city of Adelaide, South Australia. Urban Clim, 17, 89-101. doi.org/10.1016/j.uclim.2016.06.001.

16- Clinton, N.; Gong, P.( 2013), Modis detected surface urban heat islands and sinks: Global locations and controls. Remote Sens. Environ., 134, 294-304. doi.org/10.1016/j.rse.2013.03.008.

17- Dwivedi, A.; Khire, M. (2018), Application of split-window algorithm to study Urban Heat Island e_ect in Mumbai through land surface temperature approach. Sustain. Cities Soc. , 41, 865-877. doi.org/10.1016/j.scs.2018.02.030.

18- Dousset, B.; Gourmelon, F.(2003), Satellite multi-sensor data analysis of urban surface temperatures and landcover. ISPRS J. Photogramm. Remote Sens, 58, 43-54, doi:10.1016/S0924-2716(03)00016-9.

19- Flahaut, B., M. Mouchart, E. San Martin, and I. Thomas.(2003), The Local Spatial AutoCorrelation and the Kernel Method for Identifying Black Zones: A Comparative Approach. Accident Analysis \& Prevention, Vol. 35,No. 6, pp. 991-1004 doi.org/10.1016/S0001-4575(02)00107-0.

20- Fu, W. J. , Jiang, P. K. , Zhou, G. M. , Zhao, K. L.(2014), Using Moran's I and GIS to study the spatial pattern of forest litter carbon density in a subtropical region of southeastern China, Biogeosciences, 11, 2401-2409. doi.org/10.5194/bg-11-2401-2014.

21- Getis, A., and J. K. Ord.(1992), The Analysis of Spatial Association by Use of Distance Statistics. Geographic Analysis, Vol. 24, No. 3, pp. 189-206. DOI: 10.1007/978-3-64201976-0_10.

22- Grover, A., Singh, R.B.( 2015), Analysis of Urban Heat Island (UHI) in Relation to Normalized Difference Vegetation Index (NDVI): A Comparative Study of Delhi and Mumbai. Environments, 2, 125-138. doi.org/10.3390/environments2020125.

23- Guillevic, P.; Göttsche, F.; Nickeson, J.; Hulley, G.; Ghent, D.; Yu, Y.; Trigo, I.; Hook, S.; Sobrino, J.A.; Remedios, J.; Román, M.; Camacho, F.(2018),Land surface temperature product validation best practice protocol version 1.1. Good Practices for Satellite-Derived Land Product Validation. Land Product Validation Subgroup, 58, doi:10.5067/doc/ceoswgev/lpv/lst.001.

24- Grimm, N.B.; Faeth, S.H.; Golubiewski, N.E.; Redman, C.L.;Wu, J.; Bai, X.; Briggs, J.M.(2008), Global change and the ecology of cities. Science, 319, 756-760. doi: $10.1126 /$ science. 1150195 .

25- Harries, K.(2006), Extreme spatial variations in crime density in Baltimore County, MD, Geoforum, 37, 404-406. doi.org/10.1016/j.geoforum.2005.09.004.

26- Hall, D.K.; Comiso, J.C.; Digirolamo, N.E.; Shuman, C.A.; Key, J.R.; Koenig, L.S.(2012), A satellite-derived climate-quality data record of the clear-sky surface temperature of the greenland ice sheet. J. Clim. , 25, 4785-4798, doi.org/10.1175/JCLI-D-11-00365.1.

27- Hulley, G.C.; Ghent, D.; Göttsche, F.M.; Guillevic, P.C.; Mildrexler, D.J.; Coll, C.(2019), Land Surface Temperature, ISBN 9780128144589, https://doi.org/10.1016/B978-0-12814458-9.00003-4.

28- Hulley, G.; Veraverbeke, S.; Hook, S.(2014), Thermal-based techniques for land cover change detection using a new dynamic MODIS multispectral emissivity product (MOD21). Remote Sens. Environ, 140, 755-765. doi.org/10.1016/j.rse.2013.10.014.

29- Jin, M., J. M. Shepherd, and M. D. King,(2005), Urban aerosols and their interaction with clouds and rainfall: A case study for New York and Houston. J. Geophys. Res, 110, D10S20, doi:10.1029/2004JD005081.

30- Kershaw, T., Sanderson, M., Coley, D.,Eames, M.(2010), Estimation of the urban heat island for UK climate change projections. Build. Serv. Eng. Res. Technol, 31, 251-263. doi.org/10.1177/0143624410365033. 
31- Kim, Y.; Baik, J.(2005), Spatial and temporal structure of the urban heat island in Seoul. J. Appl. Meteorol, 5, 591-605. doi.org/10.1175/JAM2226.1.

32- Kustas, W.; Anderson, M.(2009), Advances in thermal infrared remote sensing for land surface modeling. Agric. For. Meteorol, 149, 2071-2081, doi:10.1016/j.agrformet.2009.05.016.

33- Levine, N.: CrimeStat III,(2004), a spatial statistics program for the analysis of crime incident locations. Ned Levine \& Associates, Houston, TX., and the National Institute of Justice, Washington, DC. doi.org/10.3886/ICPSR02824.

34- Lo, C.P., D. Quattrochi, and J. Luvall,( 1997),Application of highresolution thermal infrared remote sensing and GIS to assess the urban heat island effect, International Journal of Remote Sensing, 18:287-304. doi.org/10.1080/014311697219079.

35- Lo, C. P., \& Quattrochi, D. A.(2003), Land-Use and Land-Cover Change, Urban Heat Island Phenomenon, and Health Implications. Photogrammetric Engineering \& Remote Sensing, 69(9), 1053-1063. doi.org/10.14358/PERS.69.9.1053.

36- Mitra, S.(2009), Spatial Autocorrelation and Bayesian Spatial Statistical Method for Analyzing Fatal- and Injury-Crash-Prone Intersections. Presented at 88th Annual Meeting of the Transportation Research Board, doi.org/10.3141/2136-11.

37- Mitchell, A. (2005),The ESRI Guide to GIS Analysis. Volume 2: Spatial Measurements and Statistics. ESRI Press, Redlands, California. ISBN9781589486089, eISBN9781589486096.

38- Moran, P. A. P.(1950), Notes on continuous stochastic phenomena, Biometrika, 37, 17-23. doi.org/10.2307/2332142.

39- Menenti, M.; Bastiaanssen, W.; Van Eick, D.; El Karim, M.A,(1989), Linear relationships between surface reflectance and temperature and their appliation to map actual evaporation of groundwater. Adv. Space Res., 9, 165-176. doi.org/10.1016/0273-1177(89)90482-1.

40- Mohajerani A, Jason Bakaric J, Jeffrey-Bailey ,T ,2017) The urban heat island effect, its causes, and mitigation, with reference to the thermal properties of asphalt concrete. J Environ Manage ,197,522-538, doi.org/10.1016/j.jenvman.2017.03.095.

41- Neteler, M.; Roiz, D.; Rocchini, D.; Castellani, C.; Rizzoli, A.(2011), Terra and Aqua satellites track tiger mosquito invasion: Modelling the potential distribution of Aedes albopictus in north-eastern Italy. Int. J. Health Geogr, 10, doi.org/10.1186/1476-072X-10-49.

42- Ord, J. K., and A. Getis.(1995), Local Spatial Autocorrelation Statistics: Distributional Issues and an Application. Geographic Analysis, Vol. 27, No. 4, pp. 286-306. doi.org/10.1111/j.1538-4632.1995.tb00912.x.

43- Oke and, T. R.(1982), The energetic basis of the urban heat island. Quart. J. Roy. Meteor. Soc.1982, 108, 1-24. Doi,551 S24551.588.7.

44- Oke, T.R., R.A. Spronken-Smith, E. Jauregui, and C.S.B. Grimmond, (1999). The energy balance of central Mexico City during the dry season, Atmospheric Environment, 33:39193930. doi.org/10.1016/S1352-2310(99)00134-X.

45- Odunuga, S.; Badru, G. Landcover change, (2015), land surface temperature, surface albedo and topography in the Plateau Region of North-Central Nigeria. Land, 4, 300-324. doi.org/10.3390/land4020300.

46- O’Loughlin, J.; Witmer, F.D.W.; Linke, A.M.; Laing, A.; Gettelman, A.; Dudhia, J.( 2012), Climate variability and conflict risk in East Africa, 1990-2009. Proc. Natl. Acad. Sci. USA, 109, 18344-18349. doi.org/10.1073/pnas.1205130109.

47- Quddus, M. A.(2008), Modelling Area-Wide Count Outcomes with Spatial Correlation and Heterogeneity: An Analysis of London Crash Data. Accident Analysis \& Prevention, Vol. 40, No. 4, pp. 1486-1497,doi.org/10.1016/j.aap.2008.03.009.

48- Reisi, M.; Ahmadi Nadoushan, M.; Aye, L.(2019), Remote sensing for urban heat and cool islands evaluation in semi-arid areas. Glob. J. Environ. Sci. Manag, 5, 319-330. doi.10.22034/GJESM.2019.03.05. 
49- Rodrigues de Almeida ,C, Cláudia Teodoro ,A, Gonçalves ,A,(2021), Study of the Urban Heat Island (UHI) Using Remote Sensing Data/Techniques: A Systematic Review, Environments, 8, 105. https://doi.org/10.3390/environments8100105.

50- Rizwan, A.M.; Dennis, L.Y.C.; Liu, C.(2008), A review on the generation, determination and mitigation of urban heat island. J. Environ. Sci, 20, 120-128. doi.org/10.1016/S10010742(08)60019-4.

51- Songchitruksa, P., Zeng, X.(2010), Getis-Ord Spatial Statistics for Identifying Hot Spots Using Incident Management Data. Proceedings of Transportation Research Board 89th Annual Meeting, Washington D. C. doi.org/10.3141/2165-05.

52- Sobrino,Julien, Y.; J.A.; Mattar, C.; Ruescas, A.B.; JimeNez-Munoz, J.C.; SoRia, G.; Hidalgo, V.; Atitar, M.; Franch, B.; Cuenca, J.(2011), Temporal analysis of normalized difference vegetation index (NDVI) and land surface temperature (LST) parameters to detect changes in the Iberian land cover between 1981 and 2001. Int. J. Remote Sens., 32, 20572068. DOI: $10.1080 / 01431161003762363$.

53- Sandro M. Oswalda,e , Brigitta Hollosia, Maja Žuvela-Aloisea, Linda Seeb, Stefan Guggenbergerc, Wolfgang Hafnerc, Gundula Prokopd, Alexander Storchd, Wolfgang Schiederd,(2020) Using urban climate modelling and improved land use classifications to support climate change adaptation in urban environments: A case study for the city of Klagenfurt, Austria, journal Urban Climate, 31 , 100582, doi.org/10.1016/j.uclim.2020.100582.

54- Santamouris M (2015) Analyzing the heat island magnitude and characteristics in one hundred Asian and Australian cities and regions. Sci Total Environ, 512:582-598, doi.org/10.1016/j.scitotenv.2015.01.060.

55- Sailor, D.J.; Lu, L.(2004) A top-down methodology for developing diurnal and seasonal anthropogenic heating profiles for urban areas. Atmos. Environ., 38, 2737-2748. doi.org/10.1016/j.atmosenv.2004.01.034.

56- Streutker, D.R.(2003), Satellite-measured growth of the urban heat island of Houston, Texas. Remote Sens. Environ, 85, 282-289. doi.org/10.1016/S0034-4257(03)00007-5.

57- Schneider, P.; Hook, S.J.(2010), Space observations of inland water bodies show rapid surface warming since 1985. Geophys. Res. Lett, 37, L22405, 1-5, doi:10.1029/2010GL045059.

58- Santamouris, M.; Cartalis, C.; Synnefa, A.(2015), Local urban warming, possible impacts and a resilience plan to climate change for the historical center of Athens, Greece. Sustain. Cities Soc, 19, 281-291. doi.org/10.1016/j.scs.2015.02.001.

59- Seto, K.C.; Güneralp, B.; Hutyra, L.R.(2012), Global forecasts of urban expansion to 2030 and direct impacts on biodiversity and carbon pools. Proc. Natl. Acad. Sci. USA, 109, $16083-$ 16088. doi.org/10.1073/pnas.1211658109.

60- Tu, J. and Xia, Z. G.(2008), Examining spatially varying relationships between land use and water quality using geographically weighted regression I: Model design and evaluation, Sci Total Environ., 407, 358-378. doi.org/10.1016/j.scitotenv.2008.09.031.

61- Tobler, W. R.(1970), A Computer Movie Simulating Urban Growth in the Detroit Region, Economic Geography, Vol. 46, Supplement: Proceedings. International GeographicalUnion. Commission on Quantitative Methods, pp 234-240, http://www.jstor.org/stable/143141, doi.org/10.2307/143141.

62- Tong, H., A. Walton, J. Sang, and J.C.L. Chan, (2005). Numerical simulation of the urban boundary layer over the complex terrain of Hong Kong, Atmospheric Environment, 39:35493563. doi.org/10.1016/j.atmosenv.2005.02.045.

63- Voogt, J.A., and T.R. Oke, (1998), Effects of urban surface geometry on remotely-sensed surface temperature, International Journal of Remote Sensing, 19:895-920. doi.org/10.1080/014311698215784. 
64- Weng, Q.; Lu, D.; Schubring, J. (2004), Estimation of land surface temperature-vegetation abundance relationship for urban heat island studies. Remote Sens. Environ., 89, 467-483. doi.org/10.1016/j.rse.2003.11.005.

65- Weng, Q., (2001), A remote sensing-GIS evaluation of urban expansion and its impact on surface temperature in the Zhujiang Delta, China, International Journal of Remote Sensing, 22:1999-2014. doi.org/10.1080/713860788.

66- Weng, Q., (2003), Fractal analysis of satellite-detected urban heat island effect, Photogrammetric Engineering \& Remote Sensing, 69(5):555-566. doi.org/10.14358/PERS.69.5.555.

67- Wu, D.; Wu, H.; Zhao, X.; Zhou, T.; Tang, B.; Zhao, W.; Jia, K.(2014), Evaluation of spatiotemporal variations of global fractional vegetation cover based on GIMMS NDVI data from 1982 to 2011. Remote Sens, 6, 4217-4239. doi.org/10.3390/rs6054217.

68- Yang, L., Cao, Y.G., Zhu, X.H., Zeng, S.H., Yang, G.J., He, J.Y., \& Yang, X.C. (2014). Land surface temperature retrieval for arid regions based on Landsat-8 TIRS data: a case study in Shihezi, Northwest China. Journal of Arid Land, 6(6), 704-716. doi.org/10.1007/s40333-0140071-z.

69- Yu, K.; Chen, Y.; Wang, D.; Chen, Z.; Gong, A.; Li, J.(2019), Study of the seasonal e_ect of building shadows on urban land surface temperatures based on remote sensing data. Remote Sens, 11, 497. doi.org/10.3390/rs11050497.

70- Zaitunah, A, Samsuri , A, G Ahmad, R, A, Safitri,,2018, Normalized difference vegetation index (ndvi) analysis for land cover types using landsat 8 oli in besitang watershed, Indonesia, Earth and Environmental Science 126,012112 doi:10.1088/1755-1315/126/1/012112.

71- Zhao S, Zhou D, Liu S (2016) Data concurrency is required for estimating urban heat island intensity. Environ Pollut ,208:118-124, doi.org/10.1016/j.envpol.2015.07.037.

72- Zhou, D.; Xiao, J.; Bonafoni, S.; Berger, C.; Deilami, K.; Zhou, Y.; Frolking, S.; Yao, R.; Qiao, Z.; Sobrino, J.A.(2019), Satellite remote sensing of surface urban heat islands: Progress, challenges, and perspectives. Remote Sens, 11, 1-36, doi:10.3390/rs11010048.

73- Zhou, D.; Zhao, S.; Zhang, L.; Liu, S.(2016), Remotely sensed assessment of urbanization effects on vegetation phenology in China's 32 major cities. Remote Sens. Environ, 176, 272 281. doi.org/10.1016/j.rse.2016.02.010.

74- Zhou, D.; Zhao, S.; Liu, S.; Zhang, L.; Zhu, C.(2014), Surface urban heat island in China's 32 major cities: Spatial patterns and drivers. Remote Sens. Environ., 152, 51-61. doi.org/10.1016/j.rse.2014.05.017. 